\title{
Application of Cooperative Learning Strategies (CLS) for Students' Focused Teaching (SFT) in EFL Class: An Experimental Study in the Summer Remedial Course for Adult Learners
}

\author{
Muhammad Sabboor Hussain Raja \\ English Language Research Team, Preparatory Year Program, Qassim University, Saudi Arabia \\ Abdus Salam A. Rehman Qureshi \\ English Language Research Team, PYP, Qassim University, KSA \\ Khaled Besher Albesher \\ Deanship of Educational Services, Qassim University, Saudi Arabia
}

\begin{abstract}
Cooperative Learning Strategies (CLS) for Students Focused Teaching (SFT), known as 'studentscentered learning' (SCL), is the acknowledged pedagogical strategy. This research article is based on an experiment in an EFL class and analyses various fundamental aspects of CLS concentrating on the classroom barriers, diagnosis of students' linguistic problems and the results of the adopted strategies. During eight weeks of teaching instructions, three tests of integrated Reading and Writing skills were conducted in Level3/4 classes in Preparatory Years Program with intervals. The students were given treatment through two different methodologies viz., Cooperative Learning Strategy and Traditional Learning Strategy (TLS) in two different groups. It was hypothesized that CLS would motivate them to participate in the classroom activities. Major research findings are that to achieve teaching objectives successfully, motivated and trained teachers are required to handle the students who do not cooperate in the CLS implementation process. The study also found out other pedagogical problems in the process of implementation by comparing CLS and TLS. The comparative analysis of the experimental and the controlled groups revealed that there was no significant impact of CLS on adult EFL learners. The study discusses the factors for the lack of CLS impact on the EFL learners and gives recommendations.
\end{abstract}

Index Terms-pedagogy, cooperative learning strategies, traditional learning strategies, diagnosis, motivated teachers, linguistic needs

\section{INTRODUCTION}

\section{A. Background of the Study}

Teaching methodology as a medium that imparts knowledge to learners has gone through various phases of changes and improvements over the years. Grammar Translation Method (GTM) was considered to be the best about a hundred years ago when Latin was taught in European schools. Ever since English, Italian and French started gaining significance in the post $16^{\text {th }}$ century era, and Latin started to diminish from the scene. However, GTM had remained a dominant method of teaching a foreign language in Europe from 1840 to 1940. Gradually it was realized that GTM was not able to address the comprehensive linguistic needs of a learner because it mainly focused on reading and writing skills within the framework of strict grammatical rules, so the researchers started their efforts to find a better method to fulfil the genuine requirements of the learners.

In 1900, a new method of language teaching was introduced in Germany and France i.e., the Direct Method, also called the Natural Method because foreign language was taught naturally to the learners without the influence of the mother tongue. In this method, the element of translation from one language to another was completely banished. During the World War II, Audio-Lingual Method which is based on Behaviourist Theory was introduced. According to the proponents of this method, language was believed to be a habit formation that could be taught by the system of reinforcement, so the focus was made mainly on teaching new structures consolidating them by doing language drills.

Communicative Language Teaching (CLT) was introduced in the last quarter of $20^{\text {th }}$ century when a large population of people migrated to Europe and United States from various parts of the world mainly for jobs or permanent settlement. This huge influx of foreign workers put pressure on the educators to design a new teaching method that could help to familiarize them with the target language so that they could comfortably communicate with the people in their social or professional circles. CLT was welcomed as a useful teaching approach that could be employed in ELT because it could 
target all the four skills i.e., listening, speaking, reading and writing of a foreign language through meaningful interaction with the emphasis on communication and meaning. In fact, CLT was seen as an effective vehicle of transmission of knowledge through flexible communication.

The concept of Cooperative Learning Strategies (CLS) was introduced in the last decade of $20^{\text {th }}$ century when it was referred to by Johnson and David, the members of the Association for the Study of Higher Education (ASHE) in George Washington University (Washington D. C.) in the United States in 1991. The notion of CLS is highly socialized, interactive, modern, and communicative that involves almost all the individual students to participate actively in small groups or pairs to exchange their understanding, knowledge and expertise during the classroom activities assigned to them. In fact, it is the application of multiple minds to undertake a single or multiple but similar tasks in collaboration with their peers to achieve a common goal. This kind of learning takes place in a socialized and collaborative environment and every student plays an important role in the group to accomplish the given task. The teacher plays the role of a facilitator, an organizer, a helper and a manager of the classroom activities employing the students as the tools of teaching and communication to maximize the process of learning to achieve the desired objectives. The students cooperate with one another usually in groups or pairs in the supervision of the teacher to fulfil the activity with the help of their peers. The pedagogical support and guidance is also provided to them by the teacher whenever required so that the students may not develop any feelings of boredom, mental stress or failure.

This pedagogy focuses on the fulfilment of the linguistic needs of the students, rather than those of teachers and administrators who are directly or indirectly involved in the educational process. A teacher facilitates the learners by paying greater attention to their language deficiencies, needs, interests, previous knowledge of the subject and so on. Instead of building an entirely new edifice of knowledge, in CLS an ESL teacher polishes, renovates and expands the old building of students' knowledge on the basis of their backgrounds. To accomplish his targets, a teacher sometimes overlooks the needs of the curriculum, predetermined time for the course completion and the formal standards of teaching in Cooperative Learning Strategies.

According to ASHE-ERIC Higher Education Report-4 by Johnson and David, W. (1991), Cooperative Learning has the following basic elements that distinguish it from other teaching strategies:

1) positive interdependence

2) face to face promotional interaction

3) individuals' accountability and personal responsibility

4) frequent use of interpersonal and small groups' social skills and

5) regular group processing of current functioning

For the successful implementation of CLS, it is essential to focus on the above mentioned principles so that the maximum benefits may be achieved through the delivery of the lesson. In fact, CLT is the latest version of SFT that ensures maximum flexibility in the process of language learning. The learner enjoys maximum freedom to choose the subject matter of his own interest, develop his own learning strategies and learn according to his mental capacity by utilizing the flexible time frame. Thus it develops a sense of motivation and responsibility in the learner to achieve success.

\section{B. Scope of the Study}

Although CLS has been a very useful pedagogical method in ELT, it cannot be confined to language teaching only. In fact, the use of CLS is equally useful in teaching almost all the subjects where students can cooperate with each other in small groups in particular and with their classmates in general by exchanging and sharing their prior knowledge and experience. Likewise, CLS has been found very effective and useful method for both young as well as adult learners as they can accelerate the pace of their learning through this strategy.

Cooperative Learning Strategies (CLS) have been found very successful in primary schools where young students face problems in learning in isolation. They feel more confident in small groups with their peers and usually perform much better with enthusiasm and excitement to excel over other groups. In fact, CLS provide a platform to the students where they can display their talent explicitly in a socialized atmosphere to accomplish their academic targets. It also creates a sense of healthy competition within the group or class by playing an effective role in achieving the academic targets. However, it does not mean that the use of CLS may not be useful in an adult learners' class. In fact, adult learners can exploit this method in a much better way than young learners because they are more experienced learners and can take advantage of each other's knowledge and expertise to achieve their common academic objectives.

The place of CLS is of a great significance to anyone who is involved in the field of teaching English as a second/foreign language. Generally, the students get motivated when their individual needs are focused. They start taking interest in their lesson, work enthusiastically, and develop a positive attitude towards their studies. When they see themselves successfully accomplishing the classroom tasks along with their peers, they feel triumphant and become effective learners and willing workers in various social situations as a result. They also develop their critical thinking skills evaluating their academic position among their peers and try to improve themselves.

On the other hand, if the students find themselves neglected or less focused by the teacher, they may behave disruptively in the class. They sometimes tend to start misbehaving with the teacher and develop a negative attitude towards language learning activities. Thus the teacher fails to achieve the targets set for the successful delivery of his/her lesson. However, through the application of CLS, a teacher attaches great importance to individual students 
addressing their linguistic problems, so it is less likely for the teacher to face an embarrassing situation in the class. Consequently, the teacher succeeds in the implementation of CLS, and leads the students towards the achievements of their academic success.

Non-compliance to Cooperative Learning Strategies (CLS) forces an instructor to teach the same kind of material to all students in the class with little variations to their mental levels or learning capacity. To avoid knowledge gaps, this approach of teaching brings language inputs to all the students to the similar content in the equal span of time regardless of their previous educational background. This kind of teaching mainly focuses on the curriculum not the learner which is mostly followed in our traditional institutions. Unlike Cooperative Learning Strategies (CLS), in Traditional Learning Strategies (TLS), the students usually learn in isolation and cannot benefit from their peers' knowledge and expertise.

To achieve magnificent results in a challenging ESL class or elsewhere, a teacher has no choice but to opt for flexible learning techniques mostly found in CLS. This method strengthens students' motivation, promotes active peer communication, reduces disruptive behaviour, builds student-teacher relationships and promotes productive learning in the class. Both the students as well as teachers can reap the maximum academic benefits through the implementation of this pedagogical approach.

\section{Statement of the Problem}

Usually the techniques of various teaching methods are confused by the teachers and no line of demarcation has ever been drawn by the researchers to differentiate between them. Therefore, a need has been felt to clarify the differences between CLS and TLS so that maximum classroom benefits may be exploited by effective implementation of one of the methods. Similarly, the study also tends to indicate the possible barriers and challenges that may surface during the implementation process of CLS suggesting solutions to the practitioners to cope with them successfully. Finally, the study focuses on the results of CLS in an EFL class and compares them with the results produced from other traditional methods so that a solid conclusion may be drawn to set a priority for choosing the best possible option in an ELT class. Thus the research questions for the present study are as following:

1. What are the barriers and challenges in the implementation process of Cooperative Learning Strategies (CLS) in a language class in EFL context?

2. What are the results of the application of CLS in an EFL class and how these results are better or worse than Traditional Learning Strategies (TLS)?

\section{LITERATURE REVIEW}

The application of Cooperative Learning Strategies (CLS) is a novel thought that aims at further improvement in the previous methods of teaching. Most recently, the idea of CLS has been floated by language researchers emphasizing the need for a change in the traditional teaching environment where an average student has been found passive, apathetic and bored. According to them, it generates a sense of responsibility and ownership among the students giving them greater autonomy and control over the choice of subject matter, learning styles and pace of study as they work in groups.

Johnson, R. and David, W. (1991) state that CLS is the instructional use of small groups to make the students work together to maximize their own and each other's learning. In fact, this methodology links the process of development with the readiness of the learners to achieve better and positive results through teacher-learners' and peers' mutual interaction. Mostly the classroom activities are done in small groups with active and responsible participation of each and every member of the group. With very few limitations like slow pace of teaching, students' choice of learning method and flexible time span for course completion, the CLS has been found one of the ideal methods for teaching L2.

In connection with CLS, a phrase students focused teaching (SFT) has widely been used in research literature with different terms like students-centred learning (SCL), flexible learning, experimental learning, and self-directed learning. The idea of SFT has been credited to Hayward (1905) who used the term 'students-centred learning' for the first time in early 20th century. The term SCL is also associated with the work of Jean Piaget (1896-1980) and more recently with Malcolm Knowles (1913- 1997) (O'Sullivan 2003). In fact, SFT/SCL is a pedagogical approach that is integrated in cooperative learning strategies (CLS) where students are involved with their peers to learn and enjoy the lessons under the vigilant supervision of their teachers. Van Dat Tran (2014) strengthens these views by stating that studies involving cooperative learning (CL), one kind of student-centered approach have emerged as an internationally important area of social science research among researchers.

According to Thomas S. C. Farrell and George M. Jacobs, (2016) application of CLS demands skilful perseverance from the teacher to monitor and improvise the peers' interaction to achieve the common goals. Focus on the learners' interaction with their peers in the class is a key factor that is inevitable for successful language teaching. Marianne Celce-Murcia (2001) believes that the teachers' methodologies should be compatible with the students' learning styles. Lack of harmony between them can lead to an ultimate failure of the lesson. A language teacher should be capable enough to understand the students' individual needs making his lessons fairly attractive, communicative and fruitful. Therefore, an unskillful or untrained teacher may not be able to handle CLS successfully in an EFL class.

Jessica Townsend, Alex Dillon and Simone Sequiera (2006) opine that students-centered learning is a non-traditional process of learning that gives more freedom, flexibility and responsibility to the students to absorb information. It allows the students to choose their own style and pace of learning which suits their mental capacity. According to Min 
Han, CLS can create more interesting and relaxed atmosphere in the class that reduces the students' anxiety and promotes students-students and teacher's-students' relationships stimulating the learners' motivation and increasing their self-confidence.

Referring to the SFT, a group of teachers of the Royal Institute of Technology Stockholm, Sweden, states that teaching normally takes place during delivering the lessons, whereas learning is a synchronous or asynchronous process that is likely to be an outcome of facilitation provided by the teacher. Students can also take their own initiative to learn through peers. According to their viewpoint, classroom performance of a teacher, students' group work strategies and students' informal social interaction are some of the basic elements of conducive learning.

Referring to SFT, Jessica Townsend and others in their article on "Student-Centered Learning and Meta-cognitive Strategies" conclude: "Student centered learning is an evolving concept which promises to impart students with a thorough understanding of course materials by giving them more responsibility in the learning process. Though it could be argued that students are ultimately responsible for their leaning in any pedagogical method, traditional teaching practices frequently demand that students adapt to a specific teaching style before they can begin to truly absorb information. A central goal in student centered learning is to overcome this impasse by freeing the students to learn in the way that best suits them individually."

Identifying some of the benefits of CLS in his $\mathrm{PhD}$ research thesis, Dr. Khaled Al-Basher, one of the co-authors of this article (August 2012), says that it helps the weak students to learn from their strong counterparts as being in the same group. He further opines that it also enables the members of the group to polish some of their skills such as leadership and thinking skills encouraging the less motivated students to accomplish the task (p.18).

In fact, learning a new language is diversely complex phenomenon where students' response is rarely similar. Many factors affect the pupils' response such as their personal or family attitudes towards L2 learning, their previous learning experiences, the students-teachers' rapport, the level of enthusiasm and professionalism of the teacher etc. The proposition of CLS fulfills all these basic requirements to a great extent that are essential for productive results.

\section{METHODOLOGY}

Creswell (2009) points out, "quantitative research is a means for testing objective theories by examining the relationship among variables" (p-22). Accordingly, to compare and contrast the results of Cooperative Learning Strategy (CLS) with Traditional Learning Strategy (TLS) and to find out their implementation barriers, two groups consisting of ten students in each one of them have been chosen randomly who have been taught integrated Reading and Writing Skills for eight weeks i.e., 12 hours a week. In the Experimental Group A, CLS has been employed throughout the course with slight deviation, whereas in Controlled Group B, TLM has been used to teach the students.

The variables in the quantitative research can be measured, typically on instruments, so that numbered data can be analyzed using statistical procedures (Creswell, 2009). In order to judge the improvement of the students, a quantitative tool has been used in which three written tests have been served at different times during the course. In the first week of the Course, a pre-test was given to the students of both the groups to judge their initial level. The remaining two tests were served in the fifth and then in the eighth week at the conclusion of the course. The questions of the pre- test were designed on MCQs based on grammar such as punctuations, correct use of articles, prepositions and pronouns along with a reading comprehension passage (refer to appendix-A). Almost the same question pattern was repeated in the second test but their level was a bit difficult with some additional questions based on vocabulary, grammar and paragraph writing (refer to appendix-B). In the final test, a topic was given for writing a short essay of 12 sentences along with intermediate level comprehension passages with vocabulary and grammar (refer to appendix-C). During the final exam a questionnaire comprising ten variables was also served to record the students' feedback on both the methodologies employed during the course (refer to appendix-D) using a survey. The objective was to provide a quantitative or numeric description of trends, attitudes, or opinions of the population Creswell, 2009).

\section{DATA ANALYSis}

Apart from administering pre-test, and two post-tests viz., the mid-term and the final, a ten-item feedback survey on the Likert-scale (another quantitative research tool) was distributed to both the experimental and the controlled group. We will first discuss the responses of all the items in the feedback survey making a comparison between the experimental group and the controlled group with the help of bar charts. After this, both the groups will be analysed based on their performance in all the tests to find out the impact of cooperative learning strategies on the EFL Saudi students.

A. Analysis of the Students' Feedback 


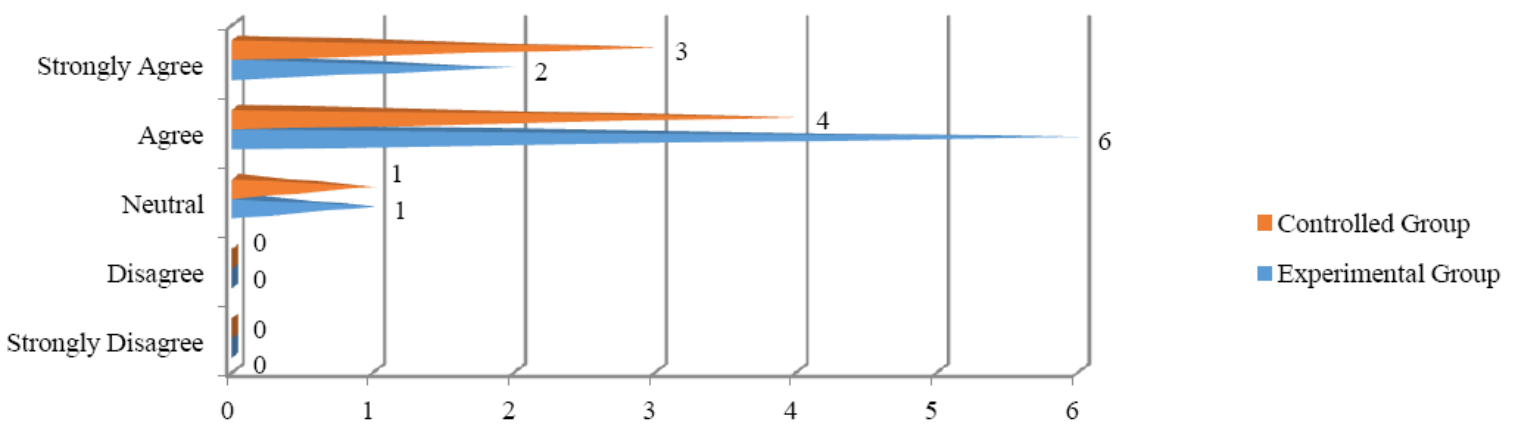

Figure 1: Item-1. I feel comfortable in cooperative learning (in groups) in Reading/Writing class because I can learn and understand in a friendly way without any stress.

In response to item number one of the survey questionnaire, majority of the students (75\%-85\%) of both the groups have expressed their positive feedback that they feel quite comfortable in Reading/Writing class while learning through CLS. Not a single student from both the groups has given a negative opinion which means that CLS is quite convenient for the students and they learn from one another's knowledge and experience. However, about $15 \%$ to $25 \%$ of the students have expressed their ignorance about the experiment mostly due to their lack of interest in their studies. Thus, it becomes quite evident that CLS is one of the most favorite and popular methods of language teaching and a majority of the EFL adult learners prefer to learn L2 through this strategy.

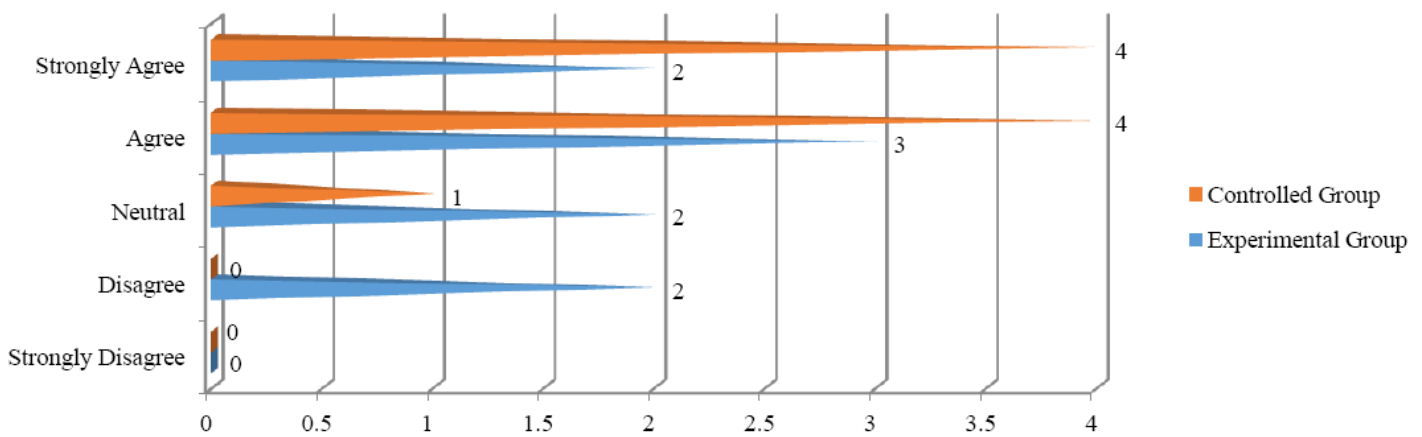

Figure 2: Item-2. In groups/cooperative learning, I enjoyed participation in the classroom activities and benefited from the knowledge and skills of my class fellows.

A difference of opinion is clearly visible in both the groups in response to survey item number two. The Controlled Group that practiced TLS believe that they can enjoy the classroom participation and benefit from the knowledge of their peers without a single disagreement. However, about $10 \%$ of the students in Controlled Group believe that they may not be able to enjoy or learn from their peers while practicing CLS. This disagreement on part of these students is perhaps due to their lack of exposure to CLS because they were taught through TLS throughout the course.

Strangely enough, about $20 \%$ of the students from Experimental Group (EG) express their negative opinion about the CLS which means that they were unable to get much benefit from the experience. Similarly, another $20 \%$ reserve their opinion about the question. Only 50\% students from EG believe that they enjoyed and benefited from their peers while practicing CLS in an EFL adult learners' class. Safely we can conclude that generally EFL students enjoy in groups and learn from the experiences of their classmates with a few exceptions.

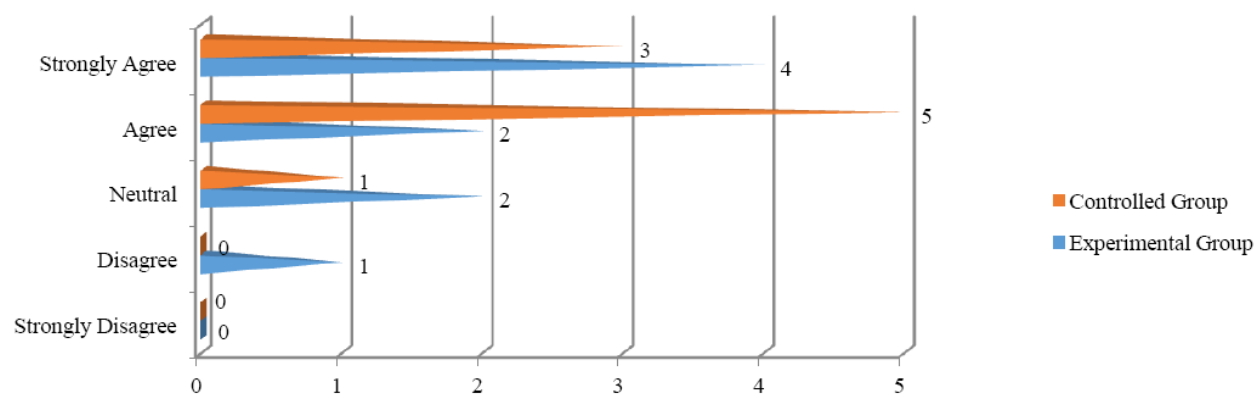

Figure 3: Item-3. Cooperative learning provided me an opportunity to make my valuable contribution to enhance my fellow students' knowledge and vice versa. 
A majority of the students in both the groups believe that CLS provides them an opportunity to share their knowledge with their peers. Through this method, the students can learn from one another's knowledge and can also make their own valuable contribution. However, approximately $10 \%$ students surprisingly expressed their disagreement from the EG which indicates that a teaching method is not always equally beneficial for all the students. Some of the exceptions are almost always found and CLS is not an exception. Therefore, the practitioners should employ all those methods which are likely to produce better results for majority of the students. Consistent application of a single method will not be the appropriate way of language teaching.

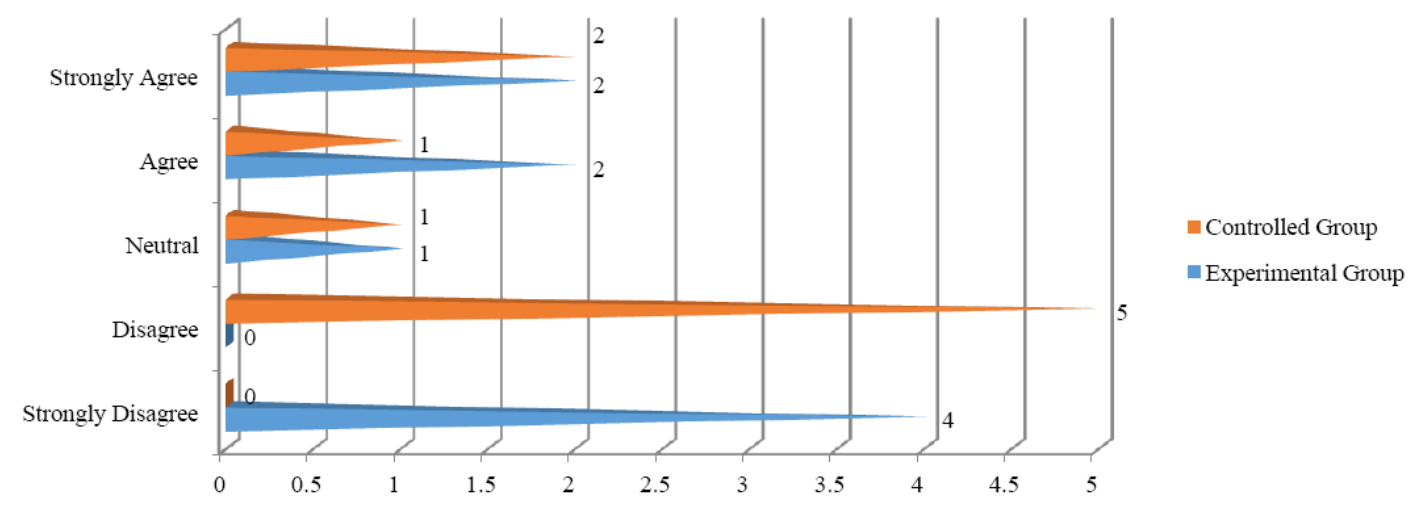

Figure 4: Item-4. In cooperative learning, students get too excited making noise in the class, so the class gets out of control for the teacher spoiling the learning process.

In response to this question, a visible majority of the students from both the groups have registered their disagreement that CLS spoils the classroom environment because of the students' excitement. In fact, a trained and an experienced teacher can handle the situation perfectly well. A noticeable point in the bar chart is the strong disagreement on the part of the EG that actually practiced CLS during the case study. It means that they have practically observed that CLS does not let the students go out of control. Rather their performance becomes more productive and useful in groups. Even the students of CG have also opted for disagreement which strengthens the idea that CLS never allows the students to get out of control spoiling the learning process. In fact, it is an effective method of teaching that enables the students to work in a conducive and friendly environment for better results. However, the teacher's personality and students' motivational level can ultimately decide the success or the failure of CLS in an EFL adult learners' class.

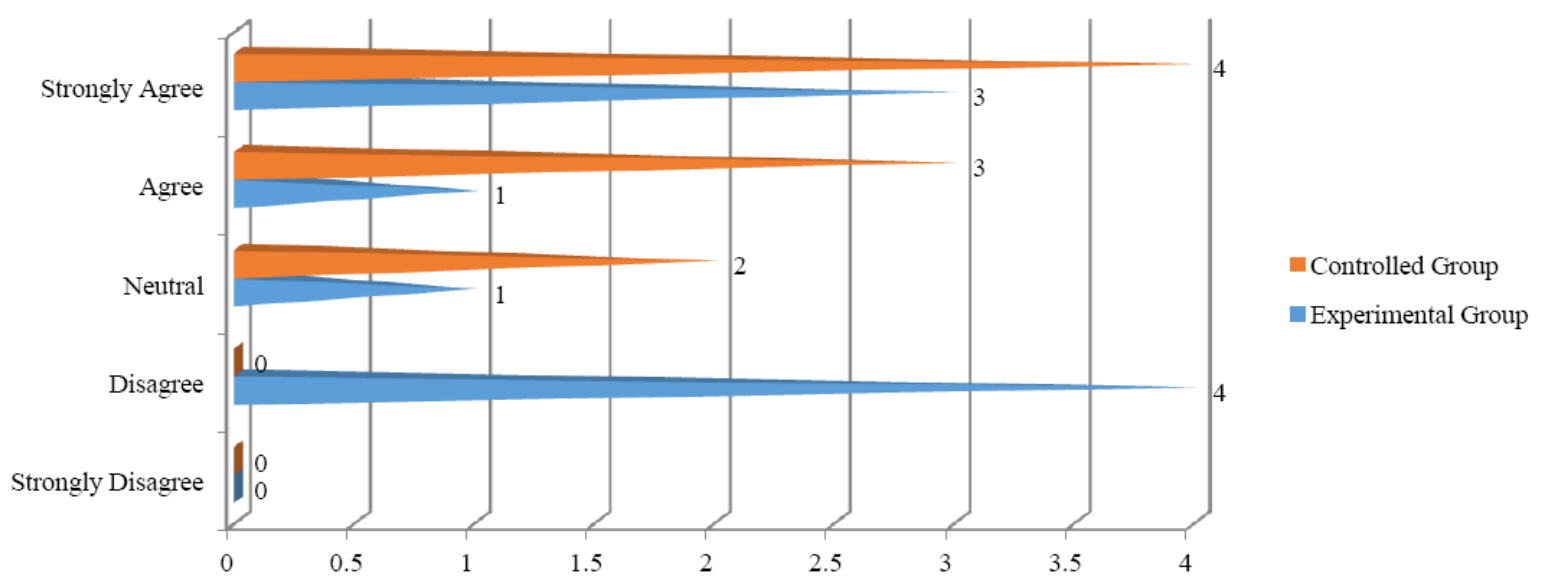

Figure 5: Item-5. Sometimes, cooperative learning strategy becomes boring; therefore, the teacher should not stick to this method only. He should employ a variety of methods to avoid repetition and boredom.

Change is the spice of life and teaching is not an exception. Due to this reason, about $80 \%$ students in the CG have opted for agreement or strong agreement in response to item number 5. They believe that various methods of teaching should be employed in an EFL adult learners' classroom to engage them meaningfully. However, the feedback of the EG is quite different. About 50\% of the students show their disagreement and record their opinion in the favor of CLS. However, 42\% students' opinion goes with the opinion of CG learners' who give their verdict in favor of the variety of methods. This scattered response indicates that the role of the teacher is vital while practicing CLS. If the teacher fails to motivate the students, they will develop their dislike for CLS. On the contrary, if the teacher is able to maintain their motivational level, CLS will prove quite effective and productive for EFL adult learners. 


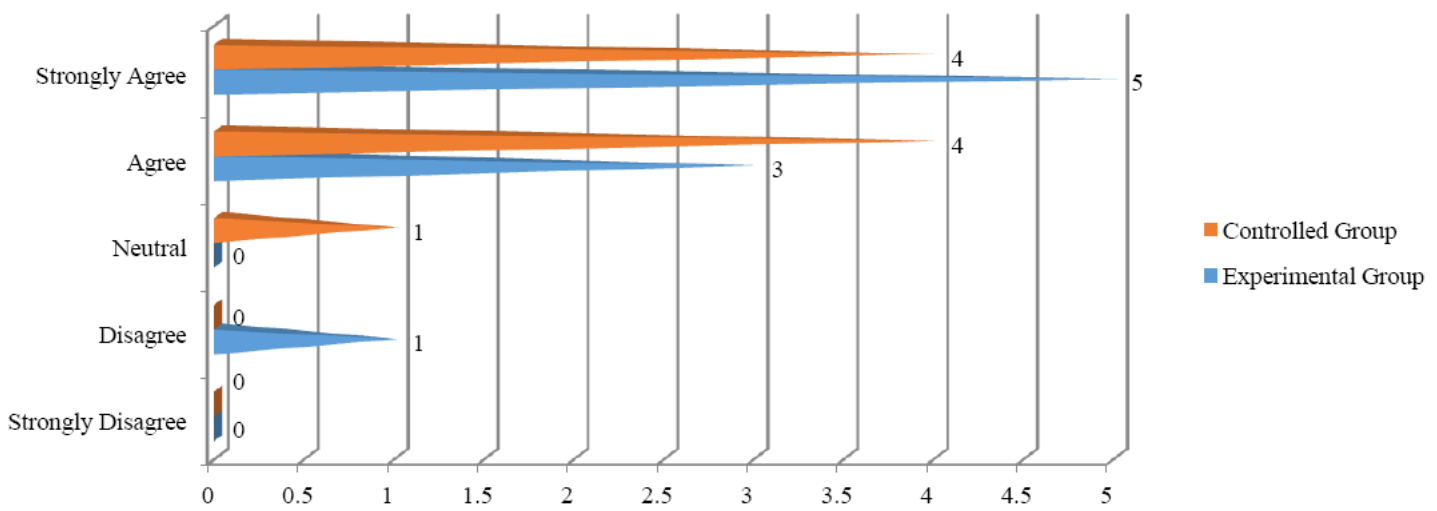

Figure 6: Item-6. The use of variety of methods including cooperative learning strategy by an English teacher helps the students to learn more effectively than by using a single method.

In response to item number six, about $90 \%$ students of both the groups have acknowledged the fact that the use of variety of teaching methods including CLS are more productive in an EFL class than a single teaching method. However, CLS should also be included among these methods. In fact, learning experience is highly laborious for the students and the use of a single teaching method sometimes loses its effectiveness. Therefore, it is very significant for the teacher to be vigilant to change his teaching method when he feels that students are losing interest in the lesson. If the teacher fails to do so, most probably his delivery of the lesson may not produce the desired results.

Responses of both the groups are quite natural and reflect human nature that always longs for a change. It has been observed that the employment of various teaching methods in an EFL/ESL class maintains the interest level of the students throughout the class which otherwise may not be possible.

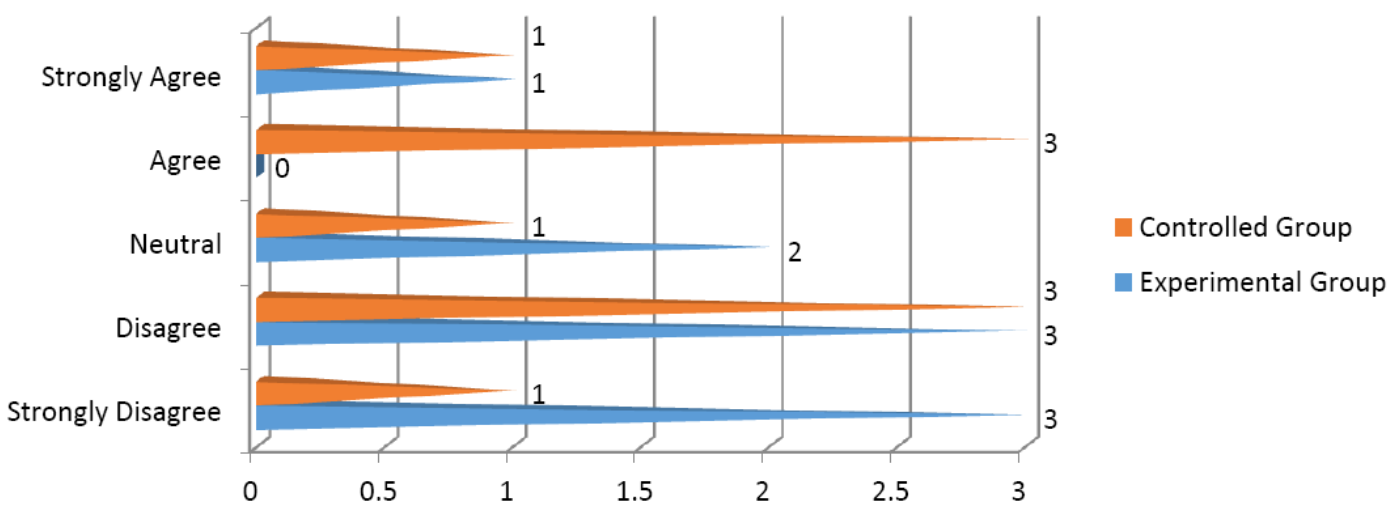

Figure 7: Item-7. I prefer to work individually in the class rather than in groups; I feel uncomfortable in group because it slows down my pace of studies.

This response on part of the $\mathrm{CG}$ is quite strange because it contradicts their previous opinion in item number one where $80 \%$ of them have opted for group learning. Here, about $50 \%$ students of CG have expressed their opinion in disagreement that they feel uncomfortable in group learning because it slows down their pace of learning. Perhaps the main reason of their disagreement emphasizes the pace of learning which usually slows down in group learning. However, in group learning intelligent students have to sacrifice their learning speed for the sake of other students' understanding.

Nevertheless, the students of EG have categorically disagreed and rejected the notion that they feel uncomfortable in group learning which proves that the Experimental Group students benefited from the CLS during the eight weeks of studies. Only $10 \%$ of them have got the opposite opinion which is quite logical. 


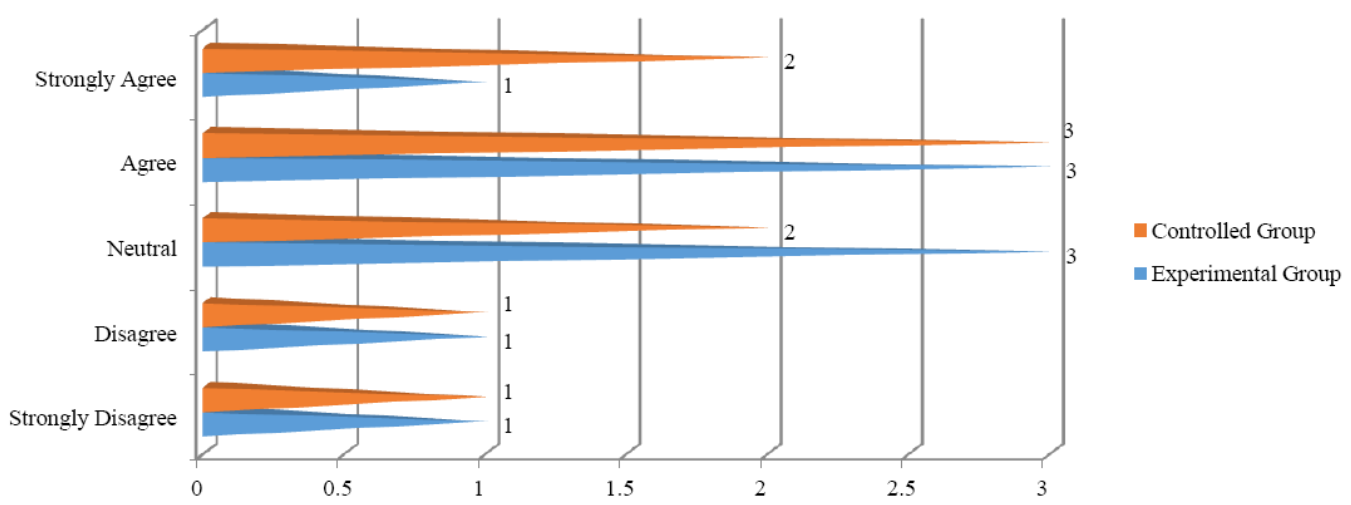

Figure 8: Item-8. Traditional learning where teacher explains everything in the class moving quickly from one exercise to another is better than cooperative learning where students are at liberty to finish their activities in flexible time.

This response of the students is another contradiction that prefers TLS over CLS. In fact, EFL students love spoon feeding; they want the teacher to do everything for them in the class which is technically wrong in an EFL/ESL class. However, about $25 \%-30 \%$ students of both the groups got confused, so they failed to opt for any option. Only $12 \%$ of them have expressed their disagreement about the statement. The responses of both the groups are almost the same that indicates that students usually try to avoid hard work and want to prefer ready made things in the class which is not recommendable. The response in item number eight, in fact, reflects one of the bitterest truths that most of the EFL adult Arab learners are mostly interested in their results instead of the acquisition of L2.

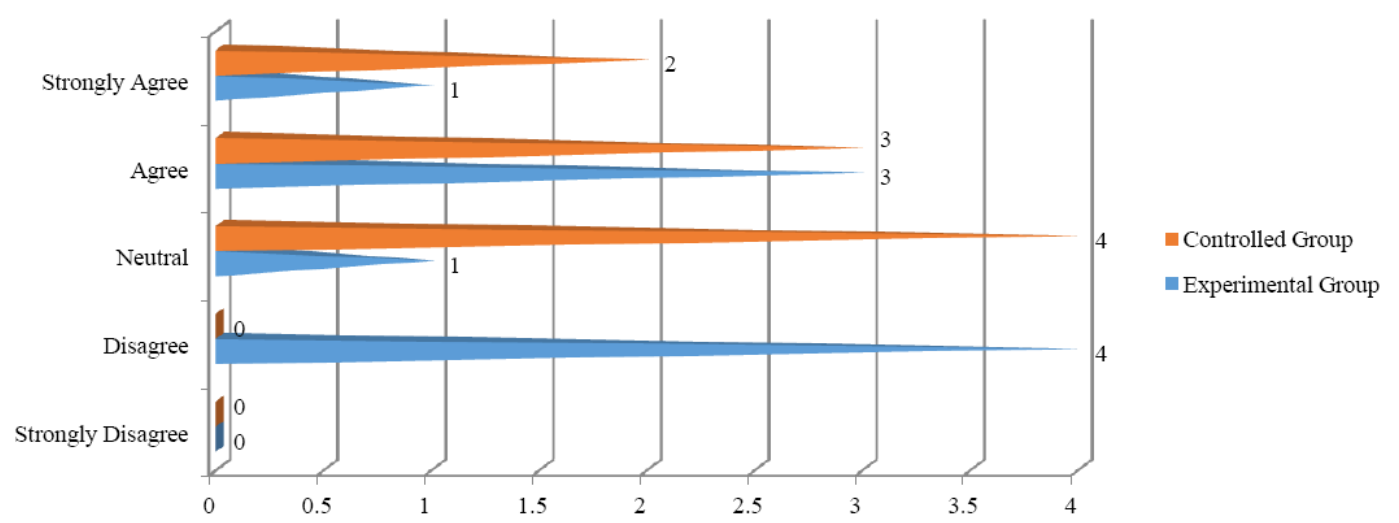

Figure 9: Item-9. I enjoyed cooperative learning more during reading comprehension activities rather than writing activities.

Students' response to item number nine is quite a new revelation which indicates that CLS is not very successful and interesting in Reading skill as compared to Writing skill. About 55\% of the students of EG believe that CLS in reading comprehension activities has not been very successful. The answer is quite logical because reading demands complete silence and concentration which students often lose in group learning. Therefore, they tend to fail in comprehending the passage. However, $27 \%$ students feel no problem in doing reading comprehension activities while being in groups.

However, the response of the CG is quite different. Because they did not practice CLS, they have no idea to comment, so $45 \%$ of the students have expressed their neutral opinion, whereas $55 \%$ believe that they enjoy reading comprehension more in groups than writing tasks which tends to be their perception because they contradict their own perception in response to item number 10 .

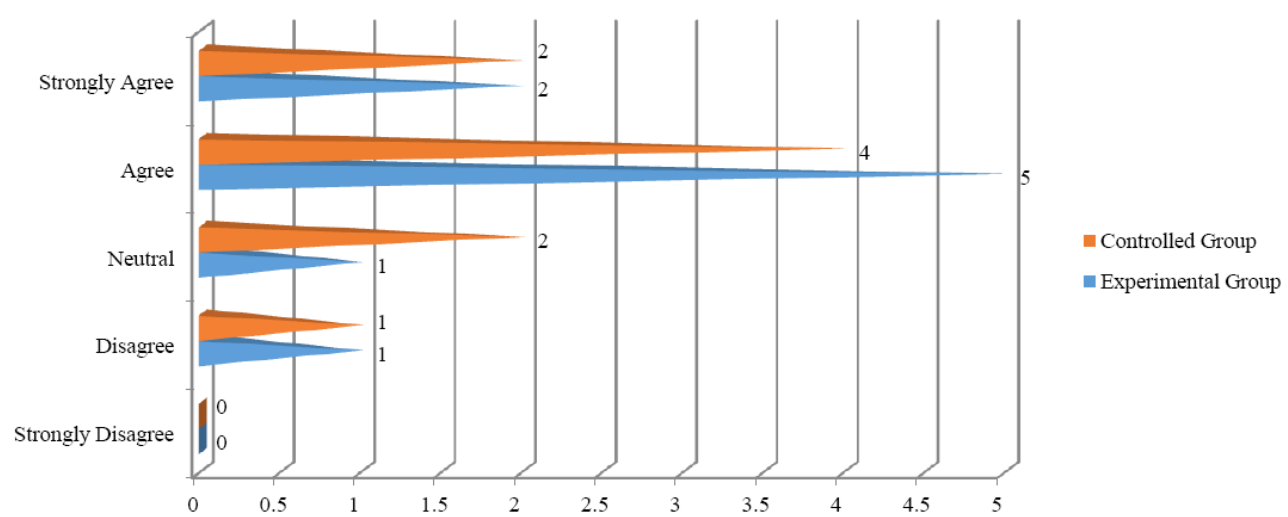

Figure 10: Item: 10. I enjoyed cooperative learning more during writing activities rather than reading comprehension activities. 
The feedback of the EG in response to item number 10 is based on their first-hand experience because they have practiced CLS both in Reading and Writing skills. About 75\% of the students opine that they enjoyed CLS more in Writing activities rather than Reading activities. Their answer is quite compatible with the previous response in item number 9. It is quite natural to enjoy writing activities in groups because students share their ideas and help one another in the formation of sentences. However, reading activities are more focused and involve individual attention for successful comprehension; therefore, some students feel uncomfortable doing them in groups. The response of the CG is almost the same but it contradicts their own views expressed earlier in item number 9 where their feedback is quite different. Apparently, it seems that this is their genuine opinion, whereas their previous opinion was perhaps a misconception.

\section{B. Statistical Analysis of the Experiment}

T-test has been conducted at three levels:

\section{Between the students' results on pre-test and post-test in the experimental group}

TABLE-1:

EXPERIMENTAL GROUP

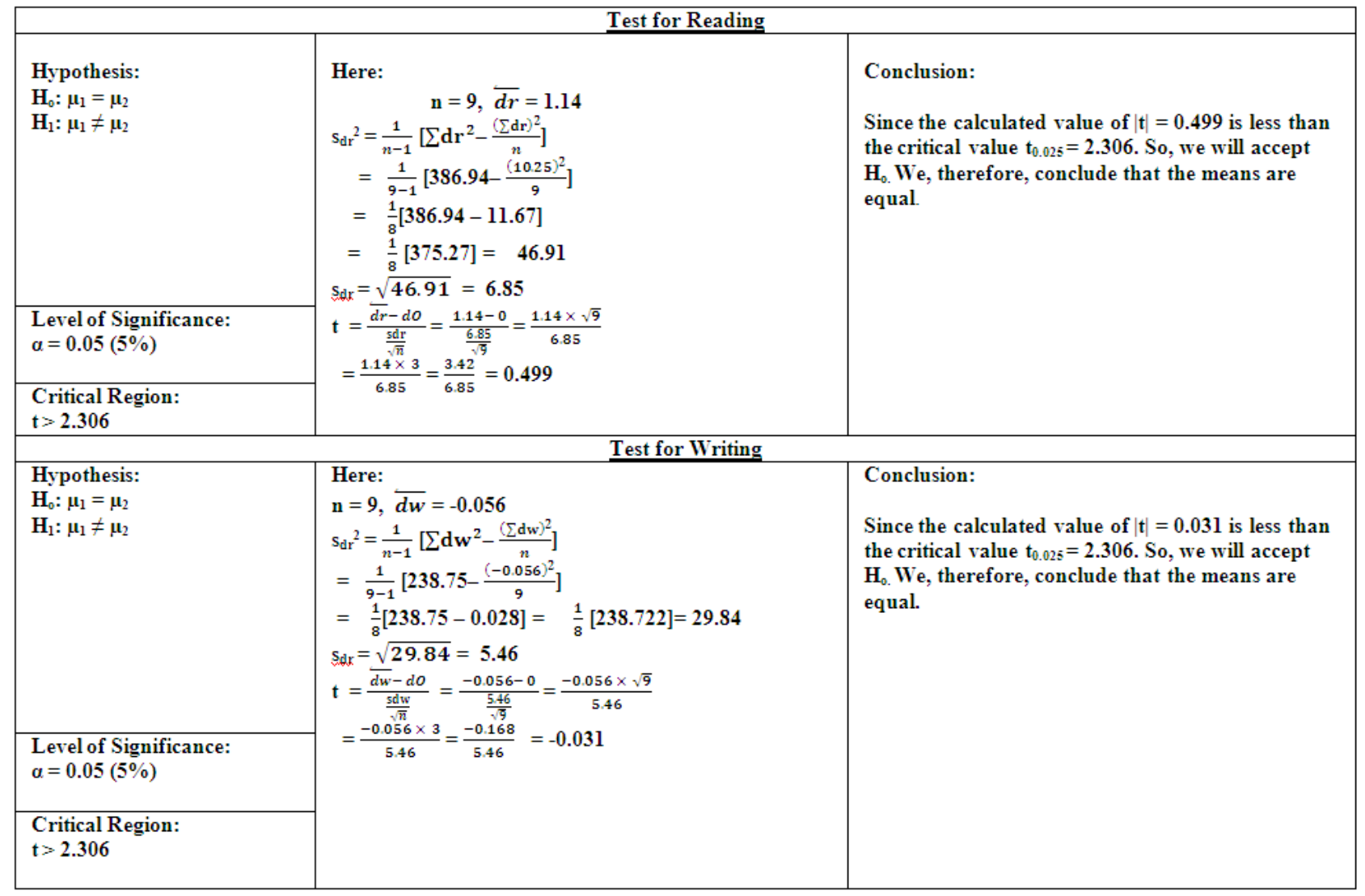

The hypothesis for this was that the students' score on post-test in both reading and writing would improve due to the cooperative learning techniques applied in teaching sessions in comparison to their scores on pre-test carried out before the teaching sessions.

The results for Reading show that the calculated value of $|t|$ is 0.499 that is less than the critical value $t_{0.025}=2.306$. In other words, the mean scores on both tests are equal. Therefore, the hypothesis stated above is proved null.

The results for Writing show that the calculated value of $|t|$ is 0.031 that is less than the critical value $t_{0.025}=2.306$. Here, too the mean scores on both tests are equal. The hypothesis is null and void. This implies that cooperative learning strategies are ineffective in teaching English to Saudi adult learners in the small classes.

\section{Between the students' results on pre-test and post-test in the controlled group}


TABLE-2:

CONTROLLED GROUP

\begin{tabular}{|c|c|c|}
\hline \multicolumn{3}{|c|}{ Test for Reading } \\
\hline $\begin{array}{l}\text { Hypothesis: } \\
\mathbf{H}_{0}: \mu_{1}=\mu_{2} \\
\mathbf{H}_{1}: \mu_{1} \neq \mu_{2}\end{array}$ & \multirow[t]{3}{*}{$\begin{array}{l}\text { Here: } \\
\mathrm{n}=9, \overline{d r}=-0.33 \\
\mathrm{~s}_{\mathrm{dr}}^{2}=\frac{1}{n-1}\left[\sum \mathrm{dr}^{2}-\frac{\left(\sum \mathrm{dr}\right)^{2}}{n}\right] \\
=\frac{1}{9-1}\left[227.63-\frac{(-3)^{2}}{9}\right]=\frac{1}{8}[227.63-1] \\
=\frac{1}{8}[226.63]=28.32 \\
\mathrm{~s}_{\mathrm{dr}}=\frac{\sqrt{28.32}}{28}=5.32 \\
\mathrm{t}=\frac{\overline{d r}-d O}{\frac{\mathrm{sdr}}{\sqrt{n}}}=\frac{-0.33-0}{\frac{5.32}{\sqrt{9}}}=\frac{-0.33 \times \sqrt{9}}{5.32}=\frac{-0.33 \times 3}{5.32} \\
=\frac{-0.99}{5.32}=-0.186\end{array}$} & \multirow[t]{3}{*}{$\begin{array}{l}\text { Conclusion: } \\
\text { Since the calculated value of }|t|=0.186 \text { is less than } \\
\text { the critical value } t_{0.025}=2.306 \text {. So, we will accept } \\
\mathbf{H}_{0} \text {. We, therefore, conclude that the means are } \\
\text { equal. }\end{array}$} \\
\hline $\begin{array}{l}\text { Level of Significance: } \\
\alpha=0.05(5 \%)\end{array}$ & & \\
\hline $\begin{array}{l}\text { Critical Region: } \\
t>2.306\end{array}$ & & \\
\hline \multicolumn{3}{|c|}{ Test for Writing } \\
\hline $\begin{array}{l}\text { Hypothesis: } \\
\mathbf{H}_{0}: \mu_{1}=\mu_{2} \\
\mathbf{H}_{1}: \mu_{1} \neq \mu_{2}\end{array}$ & \multirow[t]{3}{*}{$\begin{array}{l}\text { Here: } \\
\mathrm{n}=9, \overline{d w}=0.44 \\
\mathrm{~S}_{\mathrm{dr}^{2}}=\frac{1}{n-1}\left[\sum \mathrm{dw}^{2}-\frac{\left(\sum \mathrm{dw}\right)^{2}}{n}\right]=\frac{1}{9-1}\left[210-\frac{(4)^{2}}{9}\right] \\
=\frac{1}{8}[210-1.78]=\frac{1}{8}[208.22]=26.0275 \\
\mathrm{~S}_{\mathrm{d} \mathrm{r}}=\frac{\sqrt{26.0275}=5.102}{\mathrm{t}}=\frac{\overline{d w}-d o}{\frac{5 \mathrm{~d} w}{\sqrt{n}}}=\frac{0.44-0}{\frac{5.102}{\sqrt{9}}}=\frac{0.44 \times \sqrt{9}}{5.102}=\frac{0.44 \times 3}{5.102} \\
=\frac{1.32}{5.102}=0.2587\end{array}$} & \multirow[t]{3}{*}{$\begin{array}{l}\text { Conclusion: } \\
\text { Since the calculated value of }|t|=0.2587 \text { is less } \\
\text { than the critical value } t_{0.025}=2.306 . \text { So, we will } \\
\text { accept } H_{0} \text {. We, therefore, conclude that the means } \\
\text { are equal. }\end{array}$} \\
\hline $\begin{array}{l}\text { Level of Significance: } \\
\alpha=0.05(5 \%)\end{array}$ & & \\
\hline $\begin{array}{l}\text { Critical Region: } \\
t>2.306\end{array}$ & & \\
\hline
\end{tabular}

The hypothesis for this was that the students' score on post-test in both reading and writing would not improve much in comparison to their scores on pre-test carried out before the teaching sessions since the controlled group was not exposed to the cooperative teaching techniques.

The results for Reading show that the calculated value of $|\mathrm{t}|$ is 0.186 that is less than the critical value $\mathrm{t}_{0.025}=2.306$. In other words, the mean scores on both tests are equal. Therefore, the hypothesis stated above is accepted. The results for Writing show that the calculated value of $|\mathrm{t}|$ is 0.2587 that is less than the critical value $\mathrm{t}_{0.025}=2.306$. Here, too the mean scores on both tests are equal. The hypothesis is accepted i.e. students in controlled group have not shown much improvement even after the teaching sessions. This means that the improvement in students' performance, if sought, is possible with some intervention like introduction of advanced teaching strategies. Cooperative teaching techniques may also be of some help in this regard.

3. Results of students in controlled group and the results of students in experimental groups in pre-test and post-test 
TABLE-3:

EXPERIMENTAL GROUP VS. CONTROLLED GROUP

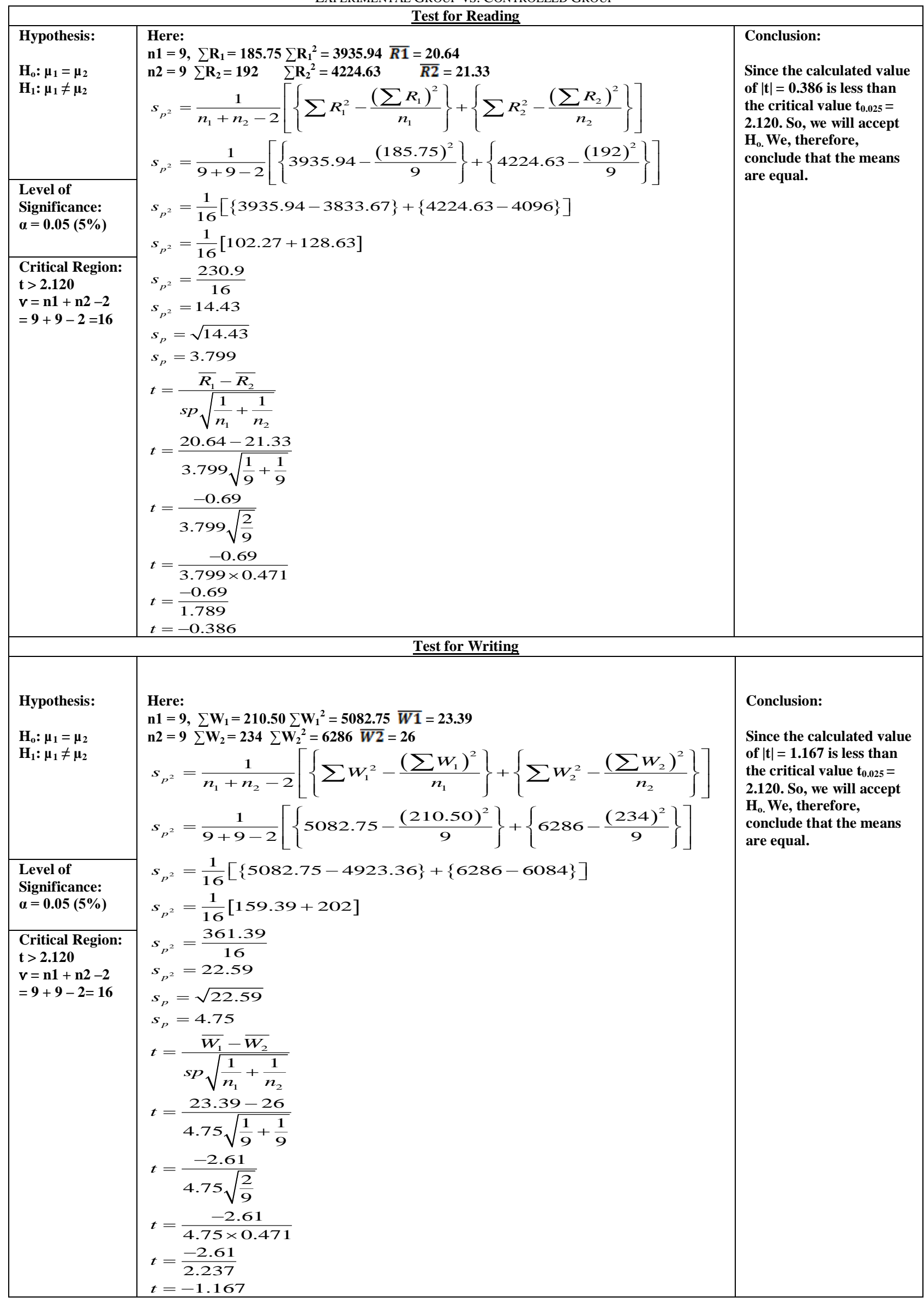


The hypothesis for this was that in experimental group, the students' score on post-test in both reading and writing would improve due to the cooperative learning techniques applied in teaching sessions in comparison to the performance of the students in the controlled group on post-test.

The results for Reading show that the calculated value of $|t|$ is 0.386 that is less than the critical value $t_{0.025}=2.120$. In other words, the mean scores on both tests are equal. Therefore, the hypothesis stated above is proved null. The results for Writing show that the calculated value of $|t|$ is 1.167 that is less than the critical value $t_{0.025}=2.120$. Here, too the mean scores on both tests are equal. The hypothesis is null and void. This shows that the intervention of cooperative learning techniques do not have a positive influence on the learning of Saudi adult English language learners in a short remedial course with small strength in the classes.

Following bar charts further elaborate the results of the experiment:

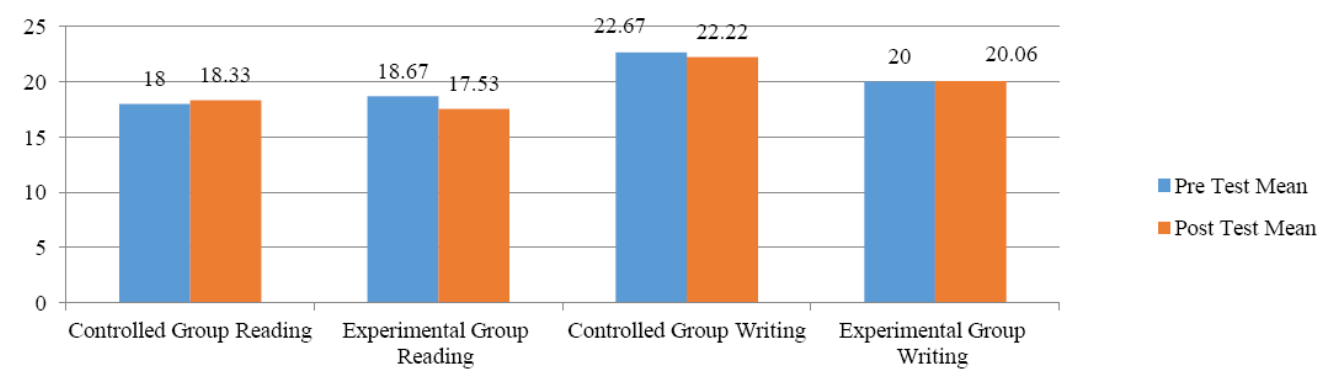

Figure 11: Comparative Analysis of Controlled and Experimental Groups' Reading Performance: Pre and Post Test Mean Scores

The bar chart above reflects a comparison of the pre-test and post-test mean scores for controlled group and experimental group. It is obvious that the controlled group shows almost the same mean score for reading on pre-test and post-test. It means that there is not any improvement in the students' performance in reading. We see almost the same results in writing. This shows that the teaching session have not been found effective in improving students' performance in reading as well as writing in controlled group. One may assume that one factor may be lack of use of cooperative learning techniques. But the assumptions is found faulty when we look at the comparison of mean scores of the students on pre-test and post-test in the experimental group who are exposed to the cooperative teaching techniques in the teaching sessions. The bar chart shows that the experimental group shows a slight improvement in writing after the teaching intervention; however, in reading, we find a rather decline in the score. This shows that Saudi adult English language learners are not interested in cooperative learning techniques.

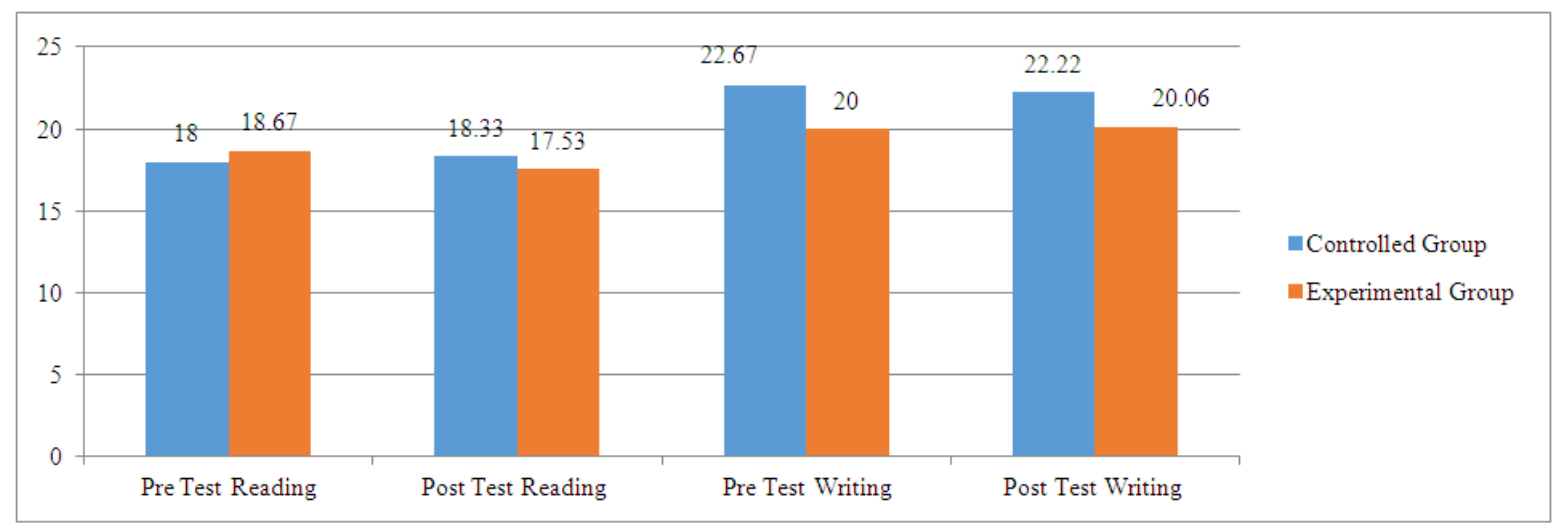

Figure 12: Comparative Analysis of Controlled and Experimental Groups’ Writing Performance: Pre and Post Test Mean Scores

This bar chart shows a comparison between controlled group and experimental group in terms of their performance on pre-test and post-test separately. We can see that in the pre-test for reading, the controlled group and experimental group have almost the same mean score; however, on writing pre-test, controlled group shows a higher mean score than the experimental group. That means that the students in the controlled group seem to be better in writing as compared to the experimental group.

The post test results for reading further show that there is a slight improvement in the mean score in case of controlled group. On the other hand, there is a slight deterioration in the mean score in the case of experimental group. In writing, the post-test 'mean scores' indicate that the controlled group shows a slight decline whereas the experimental group shows a slight improvement. However, the change is not so great that it could be said that the improvement has been mainly due to the intervention of cooperative teaching techniques.

\section{RESEARCH FINDINGS}


The experiment of implementation of CLS on the small group of adult EFL learners in the summer session remedial course apparently failed as shown in the statistical data analysis. However, the results are quite revealing and thought provoking for not only the practitioners in the teaching field but also for the future researches and researchers. Among the prime factors responsible for the failure of CLS strategies in EFL classroom, the low motivational level of the learners stands apart in importance. As a matter of fact, remedial course like summer term is usually designed to accommodate or facilitate all those students fail in the regular term or cannot appear in the exam due to some reason(s) such as shortage of class attendance, cancelation of the results due to low marks or some health issues etc. Therefore, it is quite logical to believe that most of the students who opt for summer term are not motivated; otherwise they would have passed the exam in the regular term.

Their level of motivation can also be measured from the following research findings:

a. At the outset of the course, majority of the students showed lack of punctuality by coming late to the classes. In spite of the repeated reminders of the teacher that they might be deprived of the right to appear in the exam, they did not pay any heed to the warning. Due to this reason, many planned activities had to be either cancelled or disrupted in the class due to shortage of time which could be one of the obvious factors that affected the results.

b. Since the administration's attitude towards students especially in the summer is quite lenient, they do not bother to attend the classes regularly. According to the rules, the students who fail to attend $80 \%$ lectures are usually not allowed to appear in the exam. However, this rule was not followed in letter and spirit and almost all the students were allowed to sit in the exam without evaluating their percentage of attendance specified in the rules.

c. During the classroom activities, many students seemed tired and did not show the expected enthusiasm towards the formation of groups or pairs. Some of them were not active at all in their groups to make any contribution which showed their lack of interest in the lesson. Through the inquiry, it was revealed that most of them used internet till late at night; therefore, they could not fulfill their minimum requirement of sleep that obviously affected their performance in the class as well as in the exams.

d. Throughout the course, some of the students were quite habitual in forgetting their course books at home or in their cars. Therefore, they had to share their books or teaching material with other students during the lesson. Similarly, others used to forget their pens, pencils or papers that were required for conducting writing activities. Therefore, the teacher had to supply them with the necessary material to make the lesson successful but all this was not enough to enhance their level of motivation.

e. There were ten students in each group and $80 \%$ of them in both the groups (EG \& CG) were repeaters who had failed in their regular term. Their target was neither to excel in the class nor to learn the foreign language; it was just to pass the exam by hook or by crook to continue their further studies. This negative approach on the part of the students was a great barrier in the way of their motivation that also played a role in the failure of Cooperative Learning Strategies.

f. Another important factor that could be a cause of the failure of the experiment was the strength of the students. Out of ten students in each group, 30\%-40\% were almost always found absent in the class on daily basis. Consequently, the teacher did not have much choice to put the right kind of student in the appropriate group or pair. As a result, the students lacked the necessary enthusiasm to participate properly their group or pair to accomplish the tasks that had been assigned to them. In addition, the absentees also missed some of the important lessons.

g. A tendency towards plagiarism has also been found in some of the students who tried to use the application of "Google Translation" on their cell phones by translating Arabic sentences into English ones while doing their paragraph writing activities in the class. When asked not to use their cell phones in the class, most of them were not able to complete their activities at all or had to submit them incomplete.

h. It has also been observed that sometimes the students expressed their boredom against the application of CLS in the class because of monotony, so the teacher had to deviate from the basic principles of the method to keep the lesson interesting. To avoid monotonous teaching/learning, it is recommendable that the teacher should be ready to change his teaching strategy during the lesson if he feels that the students are getting bored.

i. During the application of CLS, was observed that the students felt more comfortable in writing activities as compared to reading activities. This is proved through the students' feedback received in the survey conducted during the experiment. In writing, they exchanged ideas and discussed the formation of sentences with their peers. Even sometimes they were able to produce fairly good paragraphs on the topics. However, in reading skill, they pretended to be actively involved in the activity but the results showed otherwise because most of them failed to summarize or comprehend the passage when asked. This proves that the use of CLS is not very effective in reading skill as compared to writing skill.

j. The experiment also reveals that the students' performance in pairs was much better than in groups in the CLS experimental group. When an activity was given to them in pairs, their response was quite positive and most of them were able to accomplish it in flexible span of time. However, in groups they tried to avoid the responsibility which produced negative results.

k. Perhaps eight weeks' time in summer term as compared to the regular term where students usually attend for at least fourteen weeks is another factor that has negatively affected the results. The application of Cooperative Learning 
Strategies for such a short period of time has not been as effective as it ought to be; therefore, CLS is not an appropriate choice for summer term which is usually shorter than the regular term.

\section{CONCLUSION AND RECOMMENDATIONS}

On the basis of the research findings, it is obvious that summer term is usually conducted to facilitate the weak students of Preparatory Year Program (PYP) who, due to some reasons, fail to qualify or appear in the regular term. Therefore, it is quite natural to expect the induction of demotivated and below average students in this specially designed program. Almost all the students had either been repeaters or had been dropped in the regular term because of their deficiency in attendance. Even during this facilitated program of eight weeks, their attendance has not been ideal; most of them were at the bottom to be accepted for the exam. Moreover, being demotivated learners, their main objective was mostly confined to get through the exam so that they could further continue their studies, which was not possible without qualifying PYP course. In addition, their lack of interest could also be seen through their lethargic class participation, frequently being late or absent from the classes, going to the classes without books and stationery, using their cell phones during the lesson and so on. Even sometimes during the reading activities, some of the students did not read the passages at all neither did they participate in the group discussion. As a result, they were unable to utter a single word about the passage at the conclusion of the activity. Thus, these are some of the most valid reasons due to which the application of Cooperative Learning Strategies in EFL classes have failed to produce the desired results.

In the light of this experiment, it is highly recommended that following measures should be taken before introducing CLS in an adult EFL class:

\section{A. Selection of Students}

Perhaps the most important key to success in the application of CLS lies in the selection of the students. It is highly advisable that students should be chosen with utmost care so that they cooperate with the teacher in the class to make the learning-teaching process successful. Motivation, punctuality, tendency towards hard work and genuine desire for knowledge are the essential hallmarks that should be found in the students who are chosen for the experiment. Without having these qualities in the students, the teacher will not be able to produce the desired results through CLS.

\section{B. Reasonable Class Size}

A reasonable class size comprising 20-25 students is also necessary for the success of CLS because it promotes healthy competition among the students. The decrease or increase in the number of students in the class is likely to spoil the results. For the effective application of CLS, a teacher usually divides the students in four to five groups, which is not possible if the class size is too big or small. Therefore, it is important to maintain a reasonable class size to reap the fruits of CLS in an EFL class.

\section{Course Duration}

Generally a regular term continues for 12-14 weeks, whereas a summer term is usually 4-6 weeks shorter than the regular term. During the experiment, it has been observed that the application of CLS may not be successful for any course which is shorter than the usual time because students need more time to adjust themselves with the new and nontraditional method of teaching. Therefore, practitioners and researchers are advised not to apply CLS for an EFL course until it fulfills the minimum requirement of time i.e., 12-14 weeks.

\section{Implementation of Administrative Rules}

Academic achievements are directly linked with the strict implementation of administrative rules. No institution can achieve high standards until it is not supported by strict administrative checks. Therefore, it is essential that the rule of $80 \%$ students' attendance in the class should be strictly followed from day one. Likewise, the use of cell phones in the class and delay in class attendance or submitting assignments should be dealt with administrative checks. With the implementation of rules, the use of CLS is likely to produce much better results.

\section{E. Permissible Deviation}

The consistent application of CLS in an EFL/ESL class sometimes proves monotonous for the students who start losing interest in the lesson. Therefore, it is very important for the practitioners of the method to be vigilant and ready to deviate from the CLS and bring innovations and changes to cater for students' taste. However, the teacher should not exceed the limit; otherwise the essence of CLS will be lost which will surely affect the results. To avoid boredom and monotony in the class, about 10-25 percent deviation from CLS per week is permissible which means that a teacher can add some of the interesting flavours of other methods.

\section{F. Application of CLS in Writing}

The results of the experiment indicate that students prefer to practice CLS in a writing class rather than a reading class. Therefore, it is recommended that the method of CLS should be applied in writing classes where students can produce better results by working in small groups. However, the application of CLS in a reading class has not produced 
favourable results; therefore, it is recommended not to practice it in a reading class. Researchers can further explore its efficacy in reading and writing skills.

As a matter of fact, it is essential for an EFL/ESL teacher to employ a variety of methods in teaching process to achieve the target. During the experiment, it was also felt that some of the students showed their lack of interest in CLS at certain stages because of the repetitive way of teaching. To involve such students in the activities, sometimes the teacher is required to deviate slightly from his teaching method so that the delivery of the lesson may not become a complete failure. In a nutshell, for achieving positive results through CLS, special groups of students should be formed where motivated students are chosen with utmost care with flexible lesson plans. If the students are chosen randomly as it has been done in this experiment, the application of CLS will not produce desired results.

\section{REFERENCES}

[1] Celce-Murcia, \& Marianne. (2001). Teaching English as a Second or Foreign Language. Boston: Thomson Learning [p. 359366].

[2] Creswell, J. W. (2009). Research Design: Qualitative, Quantitative, and Mixed Methods Approach. London: SAGE Publications, Inc.

[3] Farrell, T. S., \& Jacobs, G. M. (2016). Practicing What We Preach: Teacher Reflection Groups on Cooperative Learning. TESL-EJ, 19(4), n4. [p.1-9].

[4] Han, M. (2015). An Empirical Study on the Application of Cooperative Learning to English Listening Classes. English Language Teaching, 8(3) [p.177-184].

[5] Harmer, Jerry. (2001). Practice of English Language Teaching, Pearson Educational Limited, Edinburgh, UK [p.132, 335].

[6] Johnson, David W. \& others. (1991). Cooperative Learning: Increasing College Faculty Instructional Productivity, ASHEERIC Higher Education Report No.4 1991, George Washington University, Washington D.C.

[7] Khaled Besher Albesher. (2012). Developing the writing skills of ESL students through the collaborative learning strategy, $\mathrm{PhD}$ Thesis available at: https://theses.ncl.ac.uk/dspace/bitstream/10443/1836/1/Al-Besher\%2012.pdf.

[8] O'Sullivan, M. (2003). The reconceptualization of learner-centered approaches: A Namibian case study. International Journal of Educational Development. In Press.Scrivener, Jim (1994), Learning Teaching, Macmillan Education Oxford, UK [p.6].

[9] Townsend, J., Dillon, A., Sequiera, S. (2008). Student-Centered Learning and Metacognitive Strategies in Engineering Thermal-Fluid Courses, Proceedings of the AIAA Aerospace Sciences Meeting 2008, January 6 - 9, 2008, Reno, Nevada.

[10] Tran. V. D. (2014). The effects of Cooperative Learning on the Academic Achievement and Knowledge Retention, Int. J. of Higher Education. 3(2), 131-140.

[11] Yule, George. (1986-1996). The Study of Language, Cambridge University Press, England [p.192, 193,194].

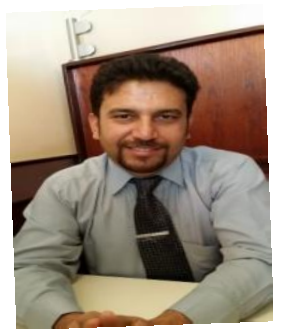

Muhammad Sabboor Hussain Raja is currently Head, English Language Research Team (ELRT), PYP, Qassim University, Saudi Arabia. He holds PhD Degree in Applied Linguistics. He has diversified experience of teaching English at different levels at various places to the adult English language learners of various nationalities. Right after doing Masters in 1998, he started teaching at his mother institute, National Institute of Modern Language, Islamabad, Pakistan as a Part Time Teacher. He served as a lecturer in English at Army Burn Hall College, Abbotabad, Pakistan, Govt. Sir Syed College, Katas, Chakwal, Pakistan, Govt. Gordon College, Rawalpindi, Pakistan and National University of Modern Languages, Islamabad, Pakistan from 1999-2005. It was in June 2005 that he was selected as Assistant Professor of English (BS-18) posted at Islamabad Model College for Boys, H-9, Islamabad, Pakistan. He has attended as well as conducted many local and international workshops and conferences on the areas of English language teaching His research interests include Psycholinguistics, Applied Linguistics, and issues related to Action Research in ELT (EFL and ESL) domain. He applies Mixed Method, Qualitative and Quantitative Approaches in his research studies. He has numerous publications in reputed journals to his credit.

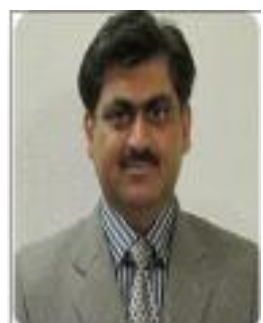

Abdus Salam A. Rehman Qureshi has been teaching English language \& literature for over two decades in various government as well as private institutions in Pakistan and abroad. He holds a Master's degree in English Literature and has been working as a Lecturer in English in Qassim University, Saudi Arabia for about a decade. During this period, he has developed a taste for research in ELT and Applied Linguistics and has officially joined English Language Research Team (ELRT) under the patronage of Deanship of Educational Services, Qassim University as an active Member. Through this forum, he has managed to have some of his articles published in international journals and has been working on several other projects to be published soon. After starting his teaching career from Pakistan in 1993, he has accumulated a valuable pedagogical experience in various countries such as Iran, United Kingdom and Saudi Arabia. For his professional development, he has regularly been attending educational seminars/workshops held from time to time. Apart from teaching, he has also worked on certain academic and administrative positions assigned to him by his employers. 


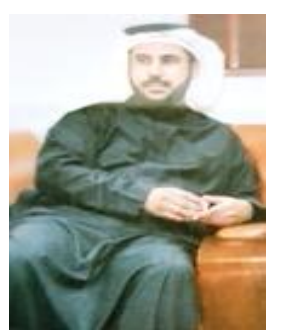

Khaled Besher Albesher is currently the dean of Deanship of Educational Services, Qassim University, Saudi Arabia. He is PhD in Applied Linguistics from the United Kingdom. His research interests include Applied Linguistics and ELT related issues particularly in the EFL context in Saudi Arabia. He has many publications in the reputed journals in his area of special interest. He is the patron in chief of English Language Research Team [ELRT] and has been the pioneer of promoting research culture in the Faculty of English Language Unit under the umbrella of Qassim University. 